\title{
A CRIANCA NA UNIDADE DE TERAPIA INTENSIVA NEONATAL: impacto da primeira visita da mãe ${ }^{a}$
}

\author{
Diana A manda PER L IN ${ }^{b}$, Stella M inasi de OLIVEIRAc, G iovana Calcagno G OM E S
}

\section{RESUMO}

O bjetivou conhecer o impacto da primeira visita à criança inter nada na U nidade de T ratamento I ntensivo $\mathrm{N}$ eonatal para sua mãe. T rata-se de uma pesquisa qual itativa real izada em um H ospital U niver sitário de agosto a novembro de 2009. Real izaram-se entrevistas semiestruturadas com dez mães. A partir da análise temática verificou-se que a primeir a visita é impactante, pois a unidade é reconhecida como um setor para o atendimento de pacientes graves; a tecnologia existente é causadora de estresse; 0 entrar desacompanhada e receber poucas informações acerca da criança pode dificultar a presença da mãe na unidade e tornar a visita assustadora ger ando sentimentos contraditórios. Sugerem a necessidade do preparo da mãe para a entrada no setor atr avés do for necimento de infor mações simples capazes de diminuir sua angústia e temor. Conclui-se necessário que a mãe seja apoiada pela equipe de saúde no momento da visita, fortalecendo seu vínculo afetivo com a criança.

D escritores: Criança hospitalizada. U nidade de terapia intensiva. F amília.

\section{RESUMEN}

E I estudio tuvo como objetivo conocer el impacto de la primera visita a los niños hospitalizados en la U nidad de Cuidados Intensivos para las madres. Se trata de una investigación cualitativa realizada en un hospital universitario de agosto a noviembre de 2009. Se realizaron entrevistas semiestructuradas con diez madres. A partir del análisis temático se encontró que la primera visita es sor prendente, porque la unidad es reconocida como lugar para el cuidado de los pacientes críticos, la tecnol ogía existentees causadora deestrés. I I sin supervisión y obtener y recibir poca información sobreel niño puedeobstaculizar la presencia de la madre en la unidad generando mi edo y sentimi entos no coincidentes. Sugier en la necesidad de preparar a la madre para entrar al sector a través de la provisión de información simple que pueda reducir su ansiedad y el miedo. Es necesario que la madre reciba apoyo del equipo de salud en el momento de la visita, para fortalecer su vínculo emocional con el niño.

D escriptores: N iño hospitalizado. U nidades de terapia intensiva. F amilia.

T ítulo: L os niños en la unidad de cuidados intensivos neonatal: el impacto de la primera visita para su madre.

\section{ABST RACT}

This study aimed to establish the impact the first visit to a child hospitalized in the $\mathrm{N}$ eonatal Intensive Care U nit have on the moher. This is a qualitative research conducted in a U niversity $\mathrm{H}$ ospital from August to $\mathrm{N}$ ovember, 2009. Semistructured interviews w ere conducted with ten mothers. T hrough thematic analysis w e found that: the first visit is striking because the unit is know $n$ as a place for the care of critically ill patients; theexisting technology causes stress; and that entering at the unit unattended and receiving little information about the child may hinder the mother's presence in the unit and make the visit frightening, leading to mixed feelings. T hey suggest the need to prepare the mothers to enter the sector through the provision of simple informations that can reduce their anxiety and fear. It is necessary that mothers be suppor ted by the healthcare staff during the visit, strengthening their emotional link with their children.

D escriptors: Child, hospitalized. Intensive care unit. F amily.

T itle: The child at the neonatal intensive care unit: the impact of the mother's first visit.

\footnotetext{
${ }^{a}$ A rtigo originado do trabal ho de conclusão do Curso de G raduação em E nfermagem da U niversidade Católica de Pel otas (U CPel), apresentado em 2009.

${ }^{b}$ Enfermeira do Serviço de N eurocirurgia do Hospital Beneficência Portuguesa de Porto Alegre, Rio Grande do Sul, Brasil.

c M estre em Enfermagem, Professora A ssistente I da U CPel, Pelotas, Rio G rande do Sul, Brasil.

d D outora em Enfermagem, Professora da E scola de Enfermagem da U niversidade Federal do Rio Grande (F U RG ), Rio Grande, Rio Grande do Sul, Brasil.
} 


\section{INT ROD UÇÃO}

0 ser mãe é um momento singular, peculiar e esperado pela grande maioria das mulheres. 0 processo de gestação e parto faz parte da vida alterando o papel social da mulher ${ }^{(1)}$.

Quando o casal decide ter um filho ou quando ocorre uma gravidez inesperada ou, até mesmo, indesejada, a possibilidade de algo dar errado durante a gestação pode causar apreensão. Caso ocorra alguma complicação poderá haver a necessidade da separação precoce da mãe e seu bebê e o momento do parto, tão aguardado, tornar-se uma situação de crise necessitando do auxílio da equipe de enfermagem para o seu enfrentamento.

Pode ocorrer um parto complicado ou prematuro, uma cesariana não programada, ou qualquer outra intercorrência tornando necessária a inter nação da criança em uma U nidade de Terapia Intensiva N eonatal (UTIN) levando à inevitável separação entre mãe e filho. A separação é causa de diver sos conflitos, pois os pais sonham com um bebê saudável ocorrendo, então, um contraste entre a criança sonhada e aquela que el es visualizam (2).

Assim, a internação da criança na UTIN causa forte impacto familiar contrastando com o que foi idealizado na gravidez, principalmente pela mãe. Estas podem apresentar sentimentos confusos e ambivalentes desencadeando uma série de fatores estressantes, sentimentos de culpa, ansiedade, medo, depressão e raiva. 0 afastamento da criança gera frustração e desapontamento e, conforme a gravidade do quadro clínico, deparam-se com um futuro incerto(3).

Sabe-se que o contato físico entre mãe e filho deve ser oportunizado precocemente por ser desencadeador de uma série de eventos fisiológicos e comportamentais que contribuem de forma positiva, sendo terapêutico para ambos ${ }^{(4)}$. No caso de internação da criança na UTIN, este contato está comprometido e as dúvidas acerca da sobrevivência da criança são, muitas vezes, associada a sentimentos de incapacidade, culpa e medo, comprometendo 0 vínculo mãe-bebê $\hat{e}^{(5)}$.

Assim, além de enfrentarem a experiência de tornarem-se mães em um contexto adverso, elas terão que enfrentar seus medos e fortalecer-se para auxiliar a criança. A hospitalização em UT IN insere o recém-nascido ( $R N$ ) em uma atmosfera inóspita, em que a exposição ao estresse e à dor é comum por meio de terapias complexas.
0 não entendimento do que está acontecendo com o filho e a sensação de que nada podem fazer para ajudá-los pode provocar o distanciamento da família(6). Durante a realização de atividades práticas em uma UTIN percebemos que as mães que ali comparecem pela primeira vez apresentamse angustiadas.

Verifica-se que à beira do leito, as mesmas apresentam-se assustadas e curiosas ao observarem o ambiente físico repleto de aparel hos e sons, talvez desconhecidos. A o fitarem a criança, no entanto, seu ol har se transmuta em afeto. Percebe-se que este momento é fundamental para o estabelecimento do vínculo mãe-bebê. Sabendo que a família constitui uma unidade de cuidado, acredita-se que ao contribuirmos para a formação do vínculo afetivo na UTIN poderemos estar incentivando esta mãe a se instrumentalizar para 0 cuidado à criança.

É necessário que as mães sejam auxiliadas pela equipe de saúde para que vivenciem a primeira visita ao bebê internado na UTIN de forma menos traumática, tendo seus medos e temores diminuídos e suas dúvidas esclarecidas, favorecendo a consolidação de sua parentalidade. N este sentido, a questão que norteou este estudo foi: Qual o impacto, da primeira visita da mãe à criança na UTIN ? A partir desta o estudo teve como objetivo conhecer o impacto da primeira visita à criança internada na UTIN para sua mãe.

\section{MÉTODOS}

Trata-se de um artigo originado de um trabal ho de conclusão de curso ${ }^{(7)}$, onde realizou-se uma pesquisa em uma UTIN de um Hospital U niversitário localizado na região Sul do estado do Rio $\mathrm{G}$ rande do Sul, com abordagem qual itativa que trabal ha com os significados, motivos, aspirações, crenças, valores e atitudes, possibilitando que o pesquisador observe os agentes no seu cotidiano, convivendo e interagindo socialmente com eles ${ }^{(8)}$.

Participaram do estudo dez mães de crianças internadas no momento da pesquisa que atenderam aos critérios de inclusão: estar vivenciando, pela primeira vez, a internação de um filho na UTIN; ser entrevistada num período máximo de 48 horas após a sua primeira visita à criança no setor; autorizar o uso de gravador no momento da entrevista e permitir a divulgação dos dados, resguardado seu anonimato. Nomes de notas musi- 
cais foram utilizadas para a identificação das entrevistadas.

Os dados foram coletados através de entrevistas semiestruturadas. A entrevista é uma atividade em que ocor re uma aproximação sucessiva da real idade que nunca se esgota ${ }^{(8)}$. Foram realizadas na própria U TIN durante a permanência das mães no setor, gravadas e transcritas para melhor captura das informações. A pós, procedeu-se a análise temática dos dados ${ }^{(8)}$ com a formulação e organização dos mesmos em categorias e interpretação à luz da liter atura consultada.

Os preceitos éticos foram mantidos de acordo com a resolução 196/ 96 do Consel ho $\mathrm{N}$ acional de Saúde ${ }^{(9)}$. As participantes assinaram o Termo de Consentimento Livre e E sclarecido e o projeto foi aprovado pelo Comitê de É tica em Pesquisa sob o nㅇ 2009/ 35.

\section{RESULTADOS E DISCUSSÃO}

Os dados foram organizados em cinco categorias: primeiro contato da mãe com a criança na UT IN ; percepções da mãe acerca do ambiente da UT I N ; sentimentos da mãe frente à criança internada na UT IN ; informações recebidas pela mãe na UT IN e sugestões da mãe para amenizar o impacto da primeira visita à criança na U TIN .

As mães entrevistadas tinham idades entre 19 e 37 anos. A idade gestacional em que se encontravam quando o bebê nasceu variava entre 24 e 39 se manas, e o número de gestações variou entre uma e cinco, sendo, apenas quatro crianças, primogênitas. Todas as entrevistadas afirmaram ter realizado o pré-natal e, apenas uma, teve parto normal.

D entre as doenças apresentadas pela mãe durante a gestação, a eclâmpsia e a pré-eclâmpsia encontraram-se em maior número, seguido de diabetes gestacional e ameaça de aborto. A prematuridade foi a principal causa de internação da criança na UTIN . O utras causas referidas pelas mães foram: infecção congênita, convulsões, meningocele e bolsa rota.

A necessidade da internação da criança na UT IN pode significar para a mãe a gravidade no seu quadro clínico e risco de morte e representar uma ameaça à integridade emocional da mãe causando sofrimento para ela e sua família. A separação da mãe e do bebê pode romper a sustentação simbólica do bebê imaginário, por fragmentar a relação mãe-filho construída ao longo da gestação e pela impossibilidade do exercício da maternagem $^{(10)}$.

\section{O primeiro contato com o R N}

A pesar de sentir-se mãe desde o momento da confirmação da gravidez, o ser mãe torna-se concreto no momento do nascimento, principalmente durante o primeiro contato pele a pele entre mãe e filho. Porém, nos casos de nascimento de uma criança que necessite de cuidados especiais logo após o nascimento, este vínculo é comprometido. Geralmente, as mães vêem a criança por um breve período de tempo antes que esta seja encaminhada para a UT IN . A ssim, a mãe refere que o contato com a criança só se efetiva no ambiente da UTIN .

Lá na sala de parto, logo que ela nasceu, ela me mostrou bem ligeirinho assim, quando ela né, saiu da minha barriga. Aí ela pegou e mostrou ligeiro e já saiu correndo com ela. E ntão eu vi bem mal, assim. E u enxerguei ela bem molhadinha, pobrezinha! (F á\#).

A qui na U TI. N a sala departo, seviu rápido (Rémenor).

É possível perceber que a atenção da equipe após o parto é centrada nas estratégias para a manutenção da vida da criança. Os cuidados prestados à criança imediatamente após o parto são essenciais para sua adaptação diminuindo a morbi-mortal idade neonatal.

Os momentos iniciais, após o parto, são uma fase sensível, precursora de apego. É a primeira oportunidade da mãe ser sensibilizada pelo seu bebê. A internação na UTIN diminui a oportunidade da mãe interagir com o RN imediatamente após o parto podendo levar ao prejuízo na formação e efetivação do apego mãe-bebê, influenciando no prognóstico do recém-nascido e na atitude da mãe durante a hospital ização(11,12).

\section{Percepções da mãe acerca do ambiente da UTIN}

A maior parte das mães participantes do estudo refere que não estavam preparadas para a necessidade de internação do RN na UT IN. Os dados evidenciam que a inter nação causa forte impacto familiar, pois esta é popularmente reconhecida como um setor para 0 atendimento de pacientes graves e com risco de morte. 
Ah, UTI pra mim é[ ...] E u sinto que estar na UTI é coisa grave, né. É essa impressão que dá. T u diz UT I, é coisa grave, tem que estar muito mal pra ir pra UTI! (Dó\#menor).

Os familiares sentem a internação na UTI como um sinal de morte iminente, talvez devido às suas experiências prévias ou as de pessoas conhecidas $^{(13)}$. No entanto, a tecnologia presente no setor é geradora de uma atmosfera de urgência tornando este ambiente impessoal e causador de estresse.

A pesar de terem consciência dos recursos que a UTIN oferece, o que mais gera impacto nas mães é o contraste entre a fragilidade da criança e a quantidade de aparelhos, sons e tubos conectados a ela.

[ ...] a gente sente um impacto assim né, de UT I, desse monte de aparelhagem, tudo né. $M$ as agora já estou mais tranquila (Sol M aior).

[ ...] mas logo que eu entrei, claro, a gente se choca sim com esse monte de a parelho (F á\#).

Estes estímulos, sonoros e táteis, provenientes dos equipamentos utilizados para a monitorização e tratamento do $\mathrm{RN}$, parecem preocupar mais os familiares do que a própria ameaça à vida da pessoa adoecida e hospitalizada ${ }^{(13)}$.

T ambém, verifica-se que 0 apoio para o enfrentamento da situação é fundamental, pois as mães que entram na unidade pela primeira vez, desacompanhadas, relatam maior impacto:

E u senti um aperto no coração né E u ol hei ela um pouco edei vol ta [ ...] não meanimei a ficar per to dela. E u vi el a tão pequenininha assim [ ...] a gentetem um impacto assim, sozinha. Se tivesse entrado al guém comigo acho que diminuiria o medo né (D ó\# menor).

Os profissionais reconhecem o despreparo dos familiares para adentrar no estranho ambiente da UTI. Esse setor pode Ihes parecer um território surreal, temido sendo de difícil entendimento ${ }^{(13)}$. A ssim, a família também pode se perceber doente neste cenário, pela desestruturação causada pela percepção de risco iminente da perda do filho ${ }^{(14)}$.

Entende-se a presença de um acompanhante na primeira visita da mãe na UTIN como um agente facilitador, pois neste contexto o forneci- mento do afeto, o contato pele-a-pele e o sonho de carregar o seu filho no colo parecem uma realidade distante para a mãe $e^{(15)}$.

\section{Sentimentos frente ao RN internado}

A primeira visita da mãe ao RN na UTIN é permeada por sentimentos ambíguos, pois ao mesmo tempo em que se sente feliz por estar próxima ao filho, também apresenta medo, tristeza e ansiedade. Evidencia-se a presença de sentimentos contraditórios que causam desorganização e angústia.

É muito ruim, é uma emoção e uma tristeza ao mesmo tempo (Si bemol).

Ah, chorei muito, estava feliz, mas foi uma sensação hor rível (M i M aior).

A internação da criança na UTIN provoca na família sentimentos de desapontamento, incapacidade, culpa e medo da perda, da situação vivenciada, que prejudicam a relação interpessoal(15). Os dados do estudo são corroborados por outros autores. E m um estudo, com mães de bebês de risco hospitalizados os autores verificaram que as mães destes vivenciam situações existenciais, às vezes contraditórias, de esperança/ desesperança, tristeza/ al egria e separação/ apego. A creditam que estes sentimentos decorrem da privação da mãe em poder desenvolver atividades de cuidado ao filho, durante a hospitalização(16).

$\mathrm{N}$ a UTIN, a família é confrontada com incertezas quanto à possibilidade da dor, quanto à necessidade de suporte à vida. 0 filho encontra-se, agora, correndo risco de morte. A realidade vivida causa forte impacto familiar podendo levar a sua desestruturação.

A h eu morri de pena assim, porque o primero impacto assim, da gente ver ele assim com aquele monte de coisinha no rosto, aqueles a par el hos né, os caninhos, aquele monte de fio ligadinho nele, assim, a gente, ah, fica pensando né, que devem estar com dor. A h eu chorava, chorava [ ...] eu ficava muito chocada, eu ia pro quar to aí, eu chorava, chorava (F á\#).

Diversos itens são citados na literatura como associados ao estresse na UTI como a presença de tubos na boca e/ ou nariz, a dor, o comprometimento do sono, a limitação de movimentos das mãos ou braços, entre outros ${ }^{(17)}$. A presença desses 
itens contribui para o estresse físico e psicológico na UTIN e para aumentar o sentimento de medo da mãe quanto à possibilidade da perda de seu fiIho.

Constata-se que há grande dificul dade na permanência das mães junto à criança durante a primeira visita. A Igumas se apresentam angustiadas e abal adas física e emocional mente, estando, ainda, fragilizadas devido ao pós-parto. No entanto, a maioria das mães conseguiu tocar na criança na primeira visita e relatou ser esta uma experiência muito boa.

Ai, eu estava até com vontade de pegar ele no colo [ risos] (Si bemol).

E u pegava na mãozinha dela, mexia nas perninhas, no pezinho dela, foi muito bom, assim. O lha, a gente nem imagina como é, assim né. E a gente gostar tanto, se apegar tanto. $\mathrm{N}$ ão tem vontade, assim, nunca mais de arredar o pé de per to ( $F$ á\#).

Sabe-se que o apego é desenvolvido desde a vida intrauterina e que este é consolidado nos momentos iniciais da vida pós-natal. $\mathrm{N}$ a situação de internação na UT IN , a diminuição do contato pode prejudicar o estabelecimento do vínculo e apego gerando desordens no relacionamento de ambos ${ }^{(16)}$. A ssim, é importante que a mãe seja estimulada a tocar e interagir com a criança diminuindo seu temor e ampliando sua segurança.

Algumas mães se sentiram limitadas durante a primeira visita, referindo terem se sentido mal no ambiente e ficado abaladas pelo estado em que encontraram a criança:

E u não me animei a ficar perto dela, eu vi ela tão pequenininha assim, eu não sei te explicar, foi uma sensação, assim, pra mim foi terrível dever ela assim. T ive medo de perder ela, tu entendesse? D e ver ela tão pe quenininha assi $m$, queela não fosseagüentar ( $D$ ó\# menor).

o nascimento prematuro ou acompanhado de doença leva a mãe a ter que fazer contato com uma realidade para a qual ainda não está preparada. A mãe pode apresentar dificuldade em se relacionar com a situação de quebra de um sonho e perigo da perda do filho. N este sentido, esta pode apresentar grande dificuldade no manuseio do bebê se sentindo desautorizada e incapaz de atuar no seu cuidado(18).

\section{Informações recebidas pela mãe na UT IN}

$\mathrm{N}$ a primeira entrada na UTI, as mães referem terem sido informadas apenas em qual berço se encontra o seu bebê.

Só disseram que ele estava aqui eque eu podia vim ver ele $\mathrm{N}$ ão disseram mais nada. F iquei assustada ao ver ele desse jeito (Lá menor).

[ ...] ela foi pra incubadora, aí eu não conseguia tocar. $\mathrm{N}$ ão sabia quepodia abrir quenem ela fez ali, queabre e bota a mão lá dentro. E u não sabia. E u ficava só olhando de cima, assim (Fá\#).

A falta de informações concretas acerca do estado da criança pode fazer com que as mães sejam surpreendidas ao verem seus filhos em uma situação que não compreendem. Percebe-se, assim, a necessidade de preparação da mãe e da família para a entrada na UTIN de for ma que compreendam a situação em que a criança se encontra, suas possibilidades e necessidades; as normas e rotinas do setor; sobre o ambiente físico da UTIN e, principalmente, da importância de sua presença junto à criança e como contribuir com a sua recuperação.

E stas infor mações poderão colabor ar para que o primeiro contato entre mãe e filho seja uma experiência prazerosa e emocionante para ambos al iviando sua angústia e aumentando sua confiança na equipe que lhe assiste.

0 profissional da saúde deve oferecer condições mínimas de conforto, respondendo às suas preocupações, oferecendo explicações sobre 0 estado de saúde, tratamento e equipamentos usados no bebê, procurando dar ênfase à criança ao invés do equipamento ou doença. A equipe deve estimular o encontro entre pais e bebês, respeitando a individualidade de cada um e sua forma de reagir neste momento dando-Ihes o apoio necessário para que sintam-se preparados para o contato com a criança $^{(4)}$.

\section{Sugestões da mãe para amenizar o impacto da primeira visita à criança na UT IN}

A o serem questionadas acerca do que poderia diminuir o impacto negativo gerado na primeira visita ao bebê na UT IN, as mães referem ser impossível não serem impactadas. 
Ai, eu acho que nada, porque pra uma mãe acho que nada ameniza ver um filho na UTI. A cho que não tem nada que possa amenizar a dor, é terrível! (Sol\# M aior).

Porém, referem importância ao preparo da família para a entrada na UT IN através de informações acerca de como a criança encontra-se.

Ah, eu acho que no quarto, assim, antes dela [ a mãe] vim pra cá, tinha que explicar né, como é que o bebezinho estava pra não ter um choque de chegar aqui ever o bebez inho entubado (Si bemol).

Evidencia-se que o simples fato da criança estar nua na incubadora ou berço aquecido pode ser fonte de grande impacto. U ma estratégia simples como mostrar uma foto do RN na UTIN antes da visita apresentou-se como importante para o seu preparo ao enfrentamento deste momento.

P ra mim ele estava vestidinho na incubadora, com roupinha. [...] Só na hora que vinham me trazer aqui [ a família] que vieram me contar [ ...] aí levei um baque, assi $m$, aquele susto de saber que ele não estava vestidinho né. Q ue a gente acha que está! (Sol M aior)

[ ...] no dia que ela nasceu ela veio pra cá direto. M eu marido tirou uma foto dela aqui e me mostrou [ ...] J á vi como ela estava, então eu não levei um choque tão grande né! (Fá \#)

Assim, percebe-se que informações simples apresentam-se como uma estratégia capaz de amenizar o impacto da primeira visita da mãe na UTIN . Para facilitar a visita da mãe à criança na UT IN recomenda-se a implantação de programas de informação e suporte psicológico aos pais ${ }^{(19)}$.

\section{CONSIDERAÇÕES FINAIS}

0 estudo evidenciou que o contraste entre a fragilidade da criança e a presença de equipamentos ligados ao seu corpo no sentido de dar-Ihe suporte à vida pode ser fonte de estresse para a mãe do R N. Assim, entrar desacompanhada e receber poucas informações prévias à visita podem dificultar a presença da mãe na unidade.

A separação da mãe e do bebê decorrente da internação na UTIN gera sentimentos contraditórios. Ao mesmo tempo em que se emocionam frente à criança sentem grande tristeza por sua si- tuação e apresentam medo de que esta sinta dor e morra, angústia pel o seu estado e incer teza do que ainda irão enfrentar.

Algumas mães, apesar de sua fragilidade física e emocional, conseguem interagir com a criança através do toque pele a pele durante a primeira visita. Outras, no entanto, devido ao seu nervosismo, estranhamento do ambiente da UT IN e gravidade do quadro clínico da criança conseguem apenas fitá-la. Verifica-se que a falta de informações acerca da criança e do setor podem tornar a primeira visita da mãe à criança mais impactante. Sugere-se que o fornecimento de informações simples é uma estratégia capaz de diminuir sua angústia e temor.

Conclui-se como fundamental que a mãe seja apoiada pela equipe de saúde atuante na UT IN tendo suas dúvidas esclarecidas e angústias diminuídas satisfazendo suas necessidades físicas e emocionais tornando o momento da visita mais prazeroso. As mães devem ser acompanhadas por um profissional da saúde durante sua primeira visita à criança e receber as informações necessárias à sua compreensão da situação vivida pela criança.

Os dados apontam que a primeira visita da mãe à criança na UT I N é impactante por isso cabe aos profissionais de saúde facilitar a vivência desse processo pela mãe, possibilitando-Ihe que assuma uma maior responsabilidade no cuidado da criança. Sendo assim, além da criança, a mãe necessita do cuidado da equipe de saúde no sentido de ser estimulada e fortalecida a participar ativamente do processo de internação da criança na UT IN , fortalecendo seu vínculo afetivo com esta.

\section{REFERÊ NCIAS}

1 Pereira ALF, M oura M AV. Ciência, natureza e nascimento humano: interfaces com o movimento de humanização do parto. Rev Eletrônica Enferm [ Internet] . 2008 [ citado 2011 abr 24] ; 10(2):537-43. Disponível em: http:/ / www.fen.ufg.br/ revista/ v10/ n2/v10n2a25.htm.

2 Simsen CD, Crossetti M G O. 0 significado do cuidado em U TI neonatal na visão de cuidadores em enfermagem. Rev G aúcha Enferm. 2004; 25(2):231-42.

3 A laves AM , G onçalves CSF, M artins M A, Silva ST, A uwerter T C, Zagonel IPS. A efetividade do cuidado solidário diante de eventos que acompanham a cronificação da doença da criança hospitalizada. Rev E letrônica E nferm [ Internet] . 2006 [ citado 2011 abr 
24] ;8(2):192-204. Disponível em: http:/ / www.fen.ufg. br/ revista/ revista8_2/ v8n2a04.htm.

4 M inistério da Saúde (BR), Secretaria de Políticas de Saúde. A tenção humanizada ao recém-nascido de baixo peso: método canguru. Brasília (DF); 2001.

5 G uimarães G P, M onticelli M A . A formação do apego pais/ recém-nascido pré-termo e/ ou de baixo peso no método mãe-canguru: uma contribuição da enfermagem. Texto Contexto Enferm [ Internet] . 2007 [ citado 2009 mar 17];16(4):626-35. Disponível em: http:/ / www.scielo.br/ pdf/ tce/ v16n4/ a06v16n4.pdf.

6 Pinheiro EM, Balbino F S, Balieiro M M FG, De D omenico E BL, Avena M J. Percepções da família do recém-nascido hospital izado sobre a comunicação de más notícias. Rev G aúcha E nferm. 2009;30(1):77-84.

7 Perlin DA 0 impacto da primeira visita à U nidade de T er apia I ntensiva $\mathrm{N}$ eonatal sobre a mãe do recém nascido [ monog rafia] . Pel otas: Centro das Ciências da Vida e da Saúde, U niversidade Católica de Pelotas; 2009.

8 M inayo M CS, organizadora. 0 desafio do conhecimento: pesquisa qualitativa em saúde. 10a ed. São PauIo: Hucitec; 2007.

9 M inistério da Saúde (BR ), Consel ho N acional de Saúde. Resolução 196, de 10 de outubro de 1996: diretrizes e normas regulamentadoras de pesquisa envolvendo seres humanos. Brasília (DF); 1996.

10 M oreno RLR, Jorge M SB. Sentimentos e emoções da mãe acompanhante no mundo da U TI: descrição fenomenológica de mudanças existenciais. Rev Enferm UERJ [ Internet] . 2005 [ citado 2011 abr 25];13:175-80. Disponível em: http:/ / www.facenf. uerj.br/v13n2/ v13n2a05.pdf.

11 Raad AJ, Cruz A M C, N ascimento M A. A realidade das mães numa unidade de ter apia intensiva neonatal. Psic Rev Psicol Vetor Ed [ Internet] . 2006 [ citado 2010 jan 13] ;7(2):85-92. Disponível em: http:/ / pepsic.bvsalud.org/ pdf/ psic/ v7n2/ v7n2a11.pdf.

12 Cruz D CS, Suman NS, Spíndola T. Os cuidados imediatos prestados ao recém-nascido e a promoção do vínculo mãe-bebê. R ev E sc E nferm U SP [ Internet] .

\section{Endereço da autora / Dirección del autor / Author's address:}

Diana A manda Perlin

Rua $\mathrm{G}$ aribaldi, 310, Centro

96195-000, Cristal, RS

E-mail:mandyperlin@hotmail.com
2007 [ citado 2011 abr 24] ;41(4):690-7. D isponível em: http:/ / www.scielo.br/ pdf/ reeusp/ v41n4/ 20.pdf.

13 Silva F S, Santos I. Expectativas de familiares de clientes em U TI sobreo atendimento em saúde: estudo sociopoético. E sc Anna N ery [ I nternet] . 2010 [ citado 2011 abr 25] ;14(2):230-5. D isponível em: http:/ / www.scielo.br/ pdf/ ean/ v14n2/ 03.pdf.

14 Cunha PJ, Zagonel IPS. A relação dialógica permeando 0 cuidado de enfermagem em UTI pediátrica cardíaca. Rev Eletrônica Enferm [ Internet]. 2006 [ citado 2009 abr 02] ;8(2):292-7. D isponível em: http:/ / www.fen.ufg.br/ revista/ revista8_2/ v8n2a 14.htm.

15 Fraga T F, A mante LN, Anders JC, Padilha M ICS, H enckemaeir L, Costa $R$, et al. Percepção das mães sobre o processo comunicacional na unidade de terapia intensiva neonatal. Rev Eletrônica Enferm [ I nter net] . 2009 [ citado 2009 nov 05] ;11(3):612-9. Disponível em: http:/ / www.fen.ufg.br/ revista/ v11/ n3/ pdf/ v11n3a19.pdf.

16 Scochi CG S, Brunherotti M R, Fonseca L M M , N ogueira FS, Vasconcel os M G L, L eite A M . L azer para mães de bebês de risco hospital izados: análise da experiência na perspectiva dessas mulheres. Rev Latino-A m E nfermagem [ I nternet] . 2004 [ citado 2011 abr 24];12(5):727-35. Disponível em: http:// www. scielo.br/ pdf/ rlae/ v12n5/ v12n5a05.pdf.

17 Bitencourt AGV, Neves FBCS, Dantas M P, Albuquerque LC, M elo RM V, Almeida A M, et al. A nálise de estressores para o paciente em U nidade de Terapia Intensiva. Rev Bras Ter Intensiva [Internet]. 2007 [ citado 2011 abr 25] ;19(1):53-9. D isponível em: http:/ / www.scielo.br/ pdf/ rbti/ v19n1/ a07v19n1.pdf.

18 Karst LT. M usicoterapia com mães de recém-nascidos internados em UTI neonatal [ dissertação] . G oiânia: U niversidade Federal de G oiás; 2004.

19 Fraga DA, Linhares M BM , Carval ho AEV, M artinez $F E$. D esenvolvimento de bebês nascidos pré-termo eindicadores emocionais maternos. Psicol Reflex Crít [ I nternet] . 2008 [ citado 2009 mar 03] ;21(1):33-41. Disponível em: http:// www.scielo.br/pdf/prc/ v2 1n1/ a05v21n1.pdf.

Recebido em: 16/ 09/ 2010

A provado em: 30/ 05/ 2011 